\title{
Plantlet Regeneration via Somatic Embryogenesis from Hypocotyls of Common Buckwheat (Fagopyrum esculentum Moench.)
}

\author{
Soo-Jeong Kwon*, Myong-Hae Han*, Yoon-Sun Huh**, Swapan Kumar Roy*, \\ Chul-Won Lee*, and Sun-Hee Woo*' \\ *Dept. of Crop Science, Chungbuk National University, Cheongju 361-763, Korea \\ **Horticultural Research Division, Chungcheongbuk-do Agricultural Research and Extension Services, \\ Cheongwon 363-882, Korea
}

\begin{abstract}
Buckwheat sprout is used as vegetable, and also flour for making noodles, and so on. Currently, information about tissue culture in buckwheat is limited and restricted to micro-propagation. We carried out somatic embryogenesis and plant regeneration using hypocotyl segments as explant of the cultivated buckwheat species, Fagopyrum esculentum which differs from existing studies in the growth regulator combinations used. Maximum callus regeneration was induced on MS medium containing 2,4-dichlorophenoxyacetic acid (2,4-D) 2.0 $\mathrm{mg} \cdot \mathrm{L}^{-1}$, benzyladenine (BA) $1.0 \mathrm{mg} \cdot \mathrm{L}^{-1}$ and $3 \%$ sucrose. Friable callus was transferred to solidified MS media containing BA $\left(1.0 \mathrm{mg} \cdot \mathrm{L}^{-1}\right)$ with various concentrations of 2,4-dichlorophenoxyacetic acid for the induction of embryogenesis. The optimum concentrations of growth regulators (for regeneration of plantlet) were indole-3-acetic acid $\left(2.0 \mathrm{mg} \cdot \mathrm{L}^{-1}\right)$, Kinetin $(1.0$ $\left.\mathrm{mg} \cdot \mathrm{L}^{-1}\right)$, BA $\left(1.0 \mathrm{mg} \cdot \mathrm{L}^{-1}\right)$. Only 2,4-D did not show any significant effect on callus induction or embryogenesis. Regeneration of embryonic callus varied from $5 \%$ to $20 \%$. Whole plants were obtained at high frequencies when the embryogenic calli with somatic embryos and organized shoot primordia were transferred to MS media with $3 \%$ sucrose. The main objective of this research was to develop an efficient protocol for plant regeneration for common buckwheat, and to apply in future for genetic transformation.
\end{abstract}

Keywords: common buckwheat, Fagopyrum esculentum, hypocotyl, somatic embryogenesis

Buckwheat, Fagopyrum esculentum Moench, is a cereal grain species of the Polygonaceae family. Buckwheat is gaining all-inclusive importance as a panorama of food crop due to its highly nutritive value. Buckwheat is pseudocereal crops, which are good source for essential amino acid like lysine, and also has excellent protein quality in terms of essential amino acid composition. It is a multipurpose crop with a variety of utilization such as food, feed, medicine and manure (Dutta et al., 2010; Han et al., 2011). It already has been proven that Buckwheat is widely adapted in China, Japan, Korea, Canada and some hilly region in the world. The crop matures in a relatively short period of time (70 to 80 days) and makes an excellent rotation with cereal grains. The regeneration of buckwheat plants via organogenesis or somatic embryogenesis from cotyledon explants has been previously reported (Neskovic et al., 1987). Now a day, there is a growing interest in common buckwheat biotechnology because in vitro techniques can provide the means for obtaining somaclones, induced variants, and genetically transformed plants, which can be used both in breeding and in biotechnological production of bioactive compounds. Somatic embryos have also proved to be excellent material for genetic transformation studies due to their competency in expressing incorporated DNA. The regeneration system is the prime importance for genetic transformation (Farzana et al., 2008). However, the procedure and efficiency of buckwheat plant regeneration was complicated and even not easily available to the scientists yet. A simple and efficient method for the regeneration of autonomous plants from tissue culture is essential to establish a genetic transformation protocol for $F$. esculentum. Buckwheat has remained a crop with low seed set due to certain characteristics which prevent the application of conventional breeding methods (Kreft, 1983). The main obstacles in buckwheat breeding include its very

\footnotetext{
${ }^{\dagger}$ Corresponding author: (Phone) +82-43-261-2515 (E-mail) shwoo@chungbuk.ac.kr

$<$ Received 13 September, 2013; Accepted 29 October, 2013 $>$
} 
strong self/cross-incompatibility and its indeterminate type of growth and flowering. Modern biotechnology may provide the means of overcoming these problems in novel ways (Neskovic et al., 1995). The main objective of this research was to develop a rapid and simple method for high efficiency plant regeneration from the hypocotyls of buckwheat.

\section{Materials and Methods}

\section{Plant material and source of explants}

Seeds of common buckwheat ( $F$. esculentum) were collected from the field at Chungbuk National University, Cheong-ju 361-763, Korea. Plants were grown during the summer when the temperature was 28 to $30^{\circ} \mathrm{C}$. The physiology of this species is timed so that plants will bloom and set seed when the hot, dry weather is over. Seeds were harvested and stored at $10^{\circ} \mathrm{C}$. An experiment of somatic embryogenesis was conducted in the Lab. of Biotechnology, Chungbuk Agricultural Research and Extension Services, Chungcheongbuk-do 363-883, Korea. Seed coats were removed and then surface sterilized for 20 second in $70 \%$ ethanol and then transferred to $0.3 \%(\mathrm{v} / \mathrm{v})$ sodium hypochlorite solution containing a drop of Tween 20 for $30 \mathrm{~min}$ and rinsed five times in sterile distilled water. The sterilized decoated seeds were germinated on growth regulators free MS liquid medium (Murashige and Skoog, 1962 ) with the support of filter paper boats. After one week of germination, hypocotyl explants were collected from germinated seedlings and used as in vitro explants and placed on callus induction medium.

\section{Callus induction and plant regeneration}

Eight combinations of auxin and cytokinin concentrations were tested for callus induction efficiency (Table 1). Approximately equal numbers (10 hypocotyls segment) of explants were placed on media containing MS salts, myoinositol $\left(100 \mathrm{mg} \cdot \mathrm{L}^{-1}\right)$, sucrose $(3 \%)$, and different combinations of 2,4-D, and BA. The $\mathrm{pH}$ was adjusted to 5.8, $0.8 \%$ agar was added, and the media were autoclaved at $121^{\circ} \mathrm{C}$ for $15 \mathrm{~min}$. Cultures were incubated in diffused light $(\sim 1200$ lux $)$ at $24^{\circ} \mathrm{C}$ and sub-cultured into fresh medium at every three weeks. For the regeneration, small fragments of friable callus were transferred to MS basal medium containing BA, kinetin, and IAA (Table 2). The somatic embryos and shoots were then transferred to halfstrength, hormone-free MS medium with 3\% sucrose.

\section{Statistical Analysis}

All experiments were set up in completely randomized block design (RCBD) and three times with 10 replicates per treatments. Statistically difference among the means was analyzed by DMRT test using PSAW ver. 17. The results are expressed as the means \pm standard error (SE) of three independent experiments.

Table 1. Effect of different concentrations of BA and 2,4-D on the induction of callus from hypocotyls of common buckwheat.

\begin{tabular}{lc}
\hline \hline Plant growth regulators & Mean of callus initiation \\
\hline BA $0.1 \mathrm{mg} \cdot \mathrm{L}^{-1}+2,4-\mathrm{D} 1.0 \mathrm{mg} \cdot \mathrm{L}^{-1}$ & $2.6 \pm 0.88^{\mathrm{c}}$ \\
BA $0.1 \mathrm{mg} \cdot \mathrm{L}^{-1}+2,4-\mathrm{D} 2.0 \mathrm{mg} \cdot \mathrm{L}^{-1}$ & $8.6 \pm 0.88^{\mathrm{ab}}$ \\
BA $0.1 \mathrm{mg} \cdot \mathrm{L}^{-1}+2,4-\mathrm{D} 4.0 \mathrm{mg} \cdot \mathrm{L}^{-1}$ & $8.0 \pm 1.52^{\mathrm{ab}}$ \\
BA $0.1 \mathrm{mg} \cdot \mathrm{L}^{-1}+2,4-\mathrm{D} 8.0 \mathrm{mg} \cdot \mathrm{L}^{-1}$ & $5.0 \pm 2.00^{\mathrm{bc}}$ \\
BA $1.0 \mathrm{mg} \cdot \mathrm{L}^{-1}+2,4-\mathrm{D} 1.0 \mathrm{mg} \cdot \mathrm{L}^{-1}$ & $9.0 \pm 1.00^{\mathrm{ab}}$ \\
BA $1.0 \mathrm{mg} \cdot \mathrm{L}^{-1}+2,4-\mathrm{D} 2.0 \mathrm{mg} \cdot \mathrm{L}^{-1}$ & $9.6 \pm 0.33^{\mathrm{a}}$ \\
BA $1.0 \mathrm{mg} \cdot \mathrm{L}^{-1}+2,4-\mathrm{D} 4.0 \mathrm{mg} \cdot \mathrm{L}^{-1}$ & $8.0 \pm 2.00^{\mathrm{ab}}$ \\
BA $1.0 \mathrm{mg} \cdot \mathrm{L}^{-1}+2,4-\mathrm{D} 8.0 \mathrm{mg} \cdot \mathrm{L}^{-1}$ & $8.3 \pm 1.20^{\mathrm{ab}}$
\end{tabular}

Data represent the mean $\pm \mathrm{SE}$ of 10 segments of hypocotyls per treatment in three repeated experiments, mean each column followed by same letter are not significantly different according to DMRT at $0.05 \%$.

Table 2. Effect of various concentrations of IAA, Kinetin, and BA on the regeneration of plantlet from hypocotyl callus of common buckwheat.

\begin{tabular}{cccc}
\hline \hline \multicolumn{3}{c}{ Hormone Concentrations } & \\
\cline { 1 - 2 } $\begin{array}{c}\mathrm{IAA} \\
\left(\mathrm{mg} \cdot \mathrm{L}^{-1}\right)\end{array}$ & $\begin{array}{c}\text { Kinetin } \\
\left(\mathrm{mg} \cdot \mathrm{L}^{-1}\right)\end{array}$ & $\begin{array}{c}\mathrm{BA} \\
\left(\mathrm{mg} \cdot \mathrm{L}^{-1}\right)\end{array}$ & Regenerated Plants \\
\hline 2.0 & 0 & 1.0 & - \\
2.0 & 0 & 5.0 & - \\
2.0 & 1.0 & 1.0 & +++ \\
2.0 & 1.0 & 5.0 & ++ \\
\hline
\end{tabular}

Plant regeneration estimated as follows: Poor (-), Very good $(++)$, and Excellent $(+++)$ 


\section{Results and Discussion}

Explants which developed on growth regulator free MS medium did not exhibit any growth. They became brown and died after a few days of culture. On medium containing growth regulators, explants after 2 weeks of culture formed calli differing by their coloration and aspect. Most of them were whitish and compact but not embryogenic. Some of them were yellowish and friable. When the calli were transferred into free growth regulator medium or into medium containing various concentrations of growth regulators, it continued to grow and did not exhibit any neo-formation. After 2 weeks, some calli altered from whitish to yellowish, friable and showed yellow light structures at their surface globular which developed into somatic embryos. In embryogenesis stages, calli showed as globular, torpedo (Fig. 1). Of the various media tested, MS supplemented with BA and 2,4-D were the best for callus induction and tissue proliferation. Prolonged maintenance on these media for up to four weeks resulted in root formation. The optimum hormone supplements were highly induced callus with minimum root at BA $1.0 \mathrm{mg} \cdot \mathrm{L}^{-1}$ and 2,4-D $2.0 \mathrm{mg} \cdot \mathrm{L}^{-1}$ in MS media containing $3 \%$ sucrose (Table $1 \&$ Fig. 1). After three-weeks of subculture period on this initiation medium, the explants were transferred to the embryo induction media. Different concentration of MS supplemented hormone such as 2,4-dichlorophenoxyacetic acid, kinetin, and benzyladenine showed good callus formation in cotyledon of common buckwheat, which is similar to our results (Woo et al., 2000).

Eight treatments were exhibited callus under diffused light condition coupled with different supplemental growth regulators, respectively. In our experiment, 2,4-D and BA is the most common growth regulator as used. Different combinations of 2,4-D and BA showed various results, which is resulted different callus percentage. According to our finding, 2,4-D showed vital responsibility with BA for callus induction. Furthermore, 2,4-D increased the number of explants which caused bud forming and embryogenic tissue, but was not essential for morphogenesis (Neskovic et al., 1987). Auxins, in particular 2,4-D, are known to promote the induction of somatic embryogenesis, whereas embryo development proceeds on the hormone depleted or hormone-free medium (Steward et al., 1970). The cytokinin

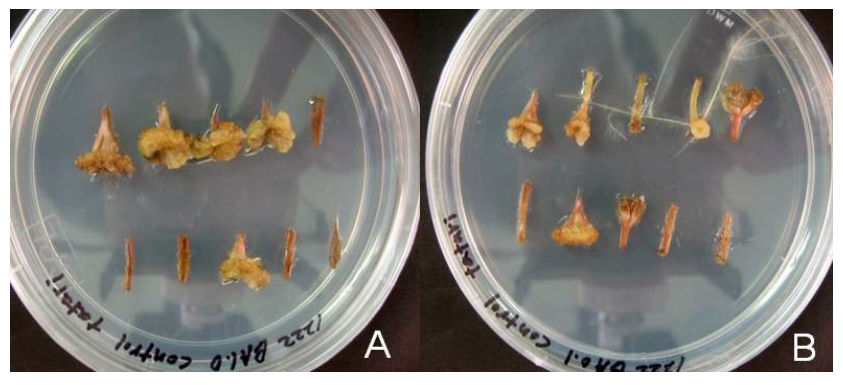

Fig. 1. Callus induction from hypocotyl segments of common buckwheat, which is effected by (A) BA $1.0 \mathrm{mg} \cdot \mathrm{L}^{-1}$ and (B) BA $0.1 \mathrm{mg} \cdot \mathrm{L}^{-1}$.

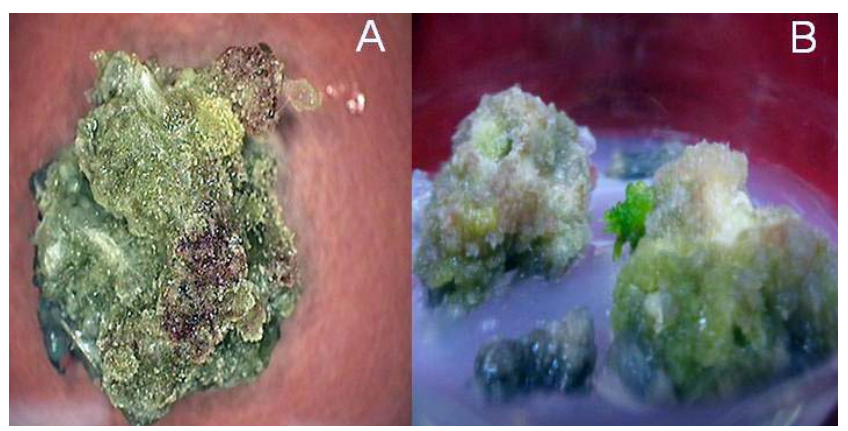

Fig. 2. Plant regeneration from embryogenic callus from hypocotyls of common buckwheat; (A) Non-embrogenic callus, (B) regeneration of shoot from somatic embryo on MS medium containing of IAA $2.0 \mathrm{mg} \cdot \mathrm{L}^{-1}$, Kinetin $1.0 \mathrm{mg} \cdot \mathrm{L}^{-1}$, BA $1.0 \mathrm{mg} \cdot \mathrm{L}^{-1}$.

as BA requirement for somatic embryo development is known to be species specific (Kohlenbach et al., 1978). Cytokinins are important for accelerating the maturation of somatic embryos and especially for cotyledon development (Ammirato et al., 1983). For embryo induction, the embryos were sub-cultured on MS media containing various concentrations of BA, Kinetin and IAA, and sucrose (3\%). After two passages on these medium at three-week interval, the calli on IAA $2.0 \mathrm{mg} \cdot \mathrm{L}^{-1}$, Kinetin $1.0 \mathrm{mg} \cdot \mathrm{L}^{-1}$ and BA 1.0 $\mathrm{mg} \cdot \mathrm{L}^{-1}$ produced well-organized nodular regions, which had a high probability of embryogenesis (Table $2 \&$ Fig. $2 \& 3)$. The non-embryogenic parts of the calli turned brown due to excessive exudation of phenolics, which polymerized to form pigments. To maintain their embryogenic potential, the white nodular segments were separated from the underlying dark translucent callus and sub-cultured on fresh medium with $0.2 \mathrm{mg} \cdot \mathrm{L}^{-1}$ Kinetin and various concentrations of BA. Between $5 \%$ and $20 \%$ of nodular 


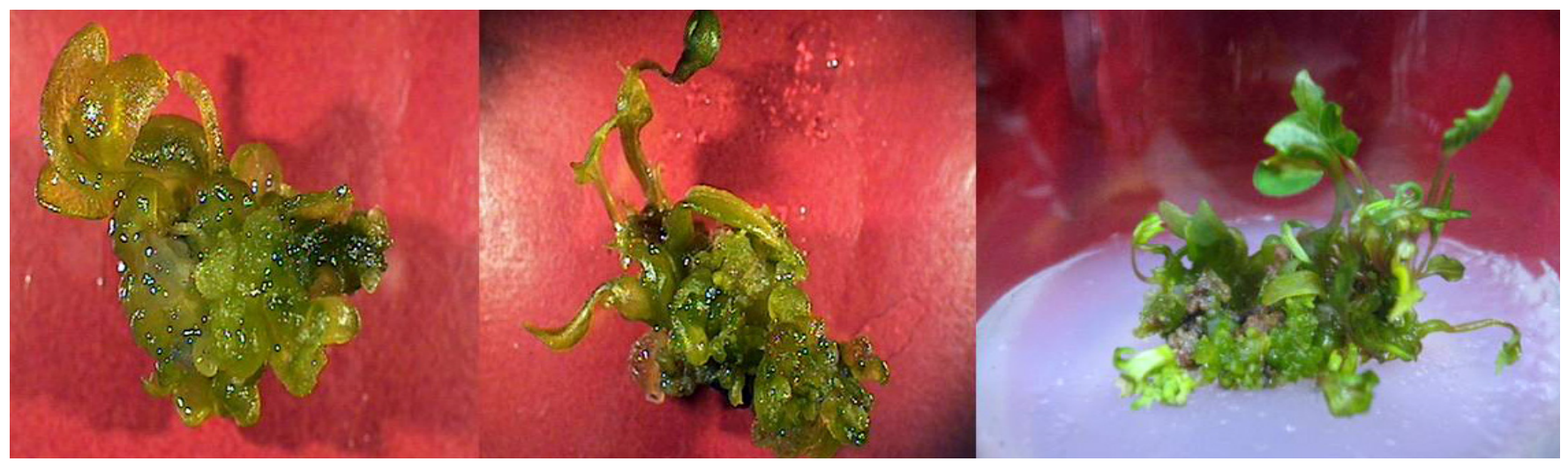

Fig. 3. Plant regeneration from embryonic callus of common buckwheat during developmental stage with enlarged hypocotyls of plantlets on the combination of IAA $2.0 \mathrm{mg} \cdot \mathrm{L}^{-1}$, Kinetin $1.0 \mathrm{mg} \cdot \mathrm{L}^{-1}$ and BA $1.0 \mathrm{mg} \cdot \mathrm{L}^{-1}$ growth regulators.

calli became embryogenic on the different media.

All treatments were maintained under diffused light conditions. The somatic embryoids were then transferred to a growth regulator free medium MS salts and sucrose $(3 \%)$. The embryos were germinated to produce plantlets. The frequency of regeneration varied with respect to the composition of the media. The highest number of plants regenerated from MS medium containing IAA $2.0 \mathrm{mg} \cdot \mathrm{L}^{-1}$, Kinetin $1.0 \mathrm{mg} \cdot \mathrm{L}^{-1}$, BA $1.0 \mathrm{mg} \cdot \mathrm{L}^{-1}$ with $3 \%$ sucrose. When medium contained sucrose alone, kinetin significantly stimulated subsequent plant regeneration in rice. Because kinetin did not necessarily benefit both the quantity and regenerative capacity for callus, the decision to include kinetin is based on genotype and the culture purpose, which is massive callus or regenerative callus (Al-Khayr et al., 1996). Various concentrations of $\mathrm{BA}$ and Kinetin showed efficient performance in shoot organogenesis in common buckwheat (Lee et al., 2009; Woo et al., 2000), which is proved our findings. The somatic embryos appeared in clusters on the embryogenic callus. At the cotyledonary stage, many embryos were very small and inconspicuous. A similar phenomenon was reported by Neskovic et al., (1995) in common buckwheat. However, in our experiments, direct regeneration of shoots also was observed occasionally. In vitro regeneration of cultivated buckwheat has been reported from a range of explant sources including: hypocotyls (Lachmann and Adachi, 1990; Woo et al., 1997; Yamane, 1974), cotyledons (Miljus-Djukic et al., 1992; Srejovic and Neskovic 1981;
Woo et al., 2000), immature inflorescences (Takahata, 1988), protoplasts (Adachi et al., 1989), and anthers (Bohanec et al., 1993). Somatic embryogenesis has occurred in cultures of immature embryos of common buckwheat (Lachmann and Adachi, 1990).

Whole plants were obtained at high frequencies when the embryogenic callus with somatic embryos and organized shoot primordia were transferred to MS media with 3\% sucrose. Best callus induction and somatic embryogenesis were observed on medium containing BA $1.0 \mathrm{mg} \cdot \mathrm{L}^{-1}$, 2,4-D $2.0 \mathrm{mg} \cdot \mathrm{L}^{-1}$, and IAA $2.0 \mathrm{mg} \cdot \mathrm{L}^{-1}$, Kinetin $1.0 \mathrm{mg} \cdot \mathrm{L}^{-1}$, BA $1.0 \mathrm{mg} \cdot \mathrm{L}^{-1}$ with $3 \%$ sucrose. The present embryogenesis system offers a highly regenerative system for common buckwheat, which could be applied for genetic transformation. Therefore, while induction was possible for most source plants, genotypic effects may still be a consideration with regard to the applicability of this technique for propagation of selected common buckwheat genotypes.

\section{ACKNOWLEDGEMENT}

This research work supported by a grant from Chungbuk National University, Korea in 2011.

\section{REFERENCES}

Adaci, T., S. Suputtitada, and Y. Miike. 1988. Plant regeneration from anther cultures in common buckwheat (Fagopyrum esculentum). Fagopyrum $8: 5-9$.

Adachi, T., A. Yamaguchi, Y. Miike, and F. Hoffmann. 1989. 
Plant regeneration from protoplasts of common buckwheat (Fagopyrum esculentum). Plant Cell Rep. 8 : 247-250.

Al-khayri, J. M., C. E. Shamblin, R. W. Mcnew, and E. J. Anderson. 1996. Callus induction and plant regeneration of U.S. Rice genotypes as affected by medium constituents. In Vitro Cell Dev. Biol-Plant. 32 : 227-232.

Ammirato, P. V. 1983. Embryogenesis, In: Evans, D. A., et al., (eds.), Handbook of Plant Cell Culture, Techniques for Propagation and Breeding, pp. 82-123, New York, Macmillan.

Bohanec, B., M. Neskovic, and R. Vujicic. 1993. Anther culture and androgenic plant regeneration in buckwheat (Fagopyrum esculentum Moench.). Plant Cell Tiss. Organ Cult. 35: 259-266.

Dutta, M. N. M., S. Shah, and P. Kumar. 2010. Assessment of agro-morphological. Physiological and genetic diversity among buckwheat cultivars. Proc. $11^{\text {th }}$ Intl. Symp. Buckwheat, Orel, Russia, 94-101.

Farzana, A. R. F., P. G. V. N. Palkadapala, K. M. M. N. Meddegoda, P. K. Samarajeewa, and J. P. Eeswara. 2008. Somatic embryogenesis in papaya (Carica papaya L. cv. Rathna). J. Nat. Sci. Found Sri Lanka 36 : 41-50.

Han, M. H., A. H. M. Kamal, Y. S. Huh, A. Y. Jeon, J. S. Bae, K. Y. Chung, M. S. Lee, S. U. Park, H. S. Jeong, and S. H. Woo. 2011. Regeneration of plantlet via somatic embryogenesis from hypocotyls of Tartary Buckwheat (Fagopyrum tataricum). Aus. J. Crop. Sci. 5 : 865-869.

Kohlenbach, H. W. 1978. Comparative somatic embryogenesis. In: Thorpe TA (Ed), Frontiers of Plant Tissue Cultures, Calgary Univ Press, Calgary

Kreft, I. 1983. Breeding breeding perspectives. In: T. Nagatomo, and T. Adachi, (eds.), Buckwheat Research 1983. Proc. $2^{\text {nd }}$ Symp. Buckwheat, Miyazaki, Japan, 113-139.

Lachmann, S. and T. Adachi. 1990. Callus regeneration from hypocotyl protoplasts of tartary buckwheat (Fagopyrum tataricum Gaertn.). Fagopyrum 10 : 62-64.

Lee, Y. K., K. Y. Kim, M. R. Uddin, N. I. Park, and S. U. Park, 2009. An efficient protocol for shoot organogenesis and plant regeneration of buckwheat (Fagopyrum esculentum
Moench.). Roman Biotech. Lett. 14:4524-4529.

Miljus-Djukic, J., M. Neskovic, S. Ninkovic, and R. Crkvenjakov. 1992. Agrobacterium-mediated transformation and plant regeneration of buckwheat (Fagopyrum esculentum Moench.). Plant Cell Tiss. Organ Cult. 15 : 473-497.

Murashige, T. and F. Skoog. 1962. A revised medium for rapid growth and bioassays with tobacco tissue cultures. Physiol. Plant. 15 : 473-497.

Neskovic, M., R. Vujicic, and S. Budimir. 1987. Somatic embryogenesis and bud formation from immature embryos of buckwheat (Fagopyrum esculentum Moench.). Plant Cell Rep. 6 : 423-426.

Neskovic, M., L. Culafic, and R. Vujicic. 1995. Somatic embryogenesis in buckwheat (Fagopyrum Mill.) and sorrel (Rumex L.), Polygonaceae. In: TPS Bajaj, (ed.), Biotechnology in agriculture and forestry, somatic embryogenesis and synthetic seeds II. pp. 412-427, Springer-Verlag, Berlin Heidleberg, New York.

Srejovic, V. and M. Neskovic. 1981. Regeneration of plants from cotyledon fragments of buckwheat (Fagopyrum esculentum Moench.). Z. Pflanzenphysiol. 104 : 37-42.

Steward, F. C., P. V. Ammirato, and M. O. Mapes. 1970. Growth and development of totipotent cells. some problems, procedures and perspectives. Ann. Bot. 34 : 761-787.

Takahata, T. 1988. Plant regeneration from cultured immature inflorescence of common buckwheat (Fagopyrum esculentum Moench.) and perennial buckwheat (F. cymosum Meisn.). Japan J. Breed. 38 : 409-413.

Woo, S. H. and T. Adachi. 1997. Production of interspecific hybrids between Fagopyrum esculentum and F. homotropicum through embryo rescue. SABRAO Genetics J. 29 : 89-95.

Woo, S. H., A. Nair, T. Adachi, and C. Campbell. 2000. Plant regeneration from cotyledon tissues of common buckwheat (Fagopyrum esculentum Moench.). In Vitro Cell. Dev. Biol-Plant, 36 : 358-361.

Yamane, Y. 1974. Induced differentiation of buckwheat plants from subcultured calluses in vitro. Japan J. Genet. 49 : 139-146. 